\title{
Calotropis procera latex proteins ameliorate functional limitations associated with adjuvant induced inflammation in rat
}

\author{
Vijay L. Kumar ${ }^{1 *}$, Priyanka Chaudhary ${ }^{2}$, Renato M. Oliveira ${ }^{3}$ and Marcio V. Ramos ${ }^{3}$ \\ *Correspondence: kumarvl98@hotmail.com

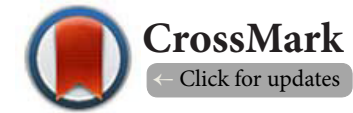 \\ 'Department of Pharmacology, All India Institute of Medical Sciences, New Delhi, India. \\ ${ }^{2}$ Department of Plant Molecular Biology, Delhi University South Campus, New Delhi, India. \\ ${ }^{3}$ Department of Biochemistry and Molecular Biology, Federal University of Ceara, Fortaleza, Brazil.
}

\begin{abstract}
Background: Proteins isolated from the latex (LP) of Calotropis procera (family: Apocynaceae) have been shown to ameliorate inflammatory hyperalgesia in the rat model of Freund's Complete Adjuvant (FCA) induced monoarthritis. The objective of the present study was to evaluate the effect of LP on inflammation index and time of functional recovery in arthritic rats.

Methods: Monoarthritis was induced by intra-articular injection of FCA and joint diameter, motility, stair climbing ability and dorsal flexion pain scores were recorded before inducing arthritis and thereafter at different time intervals till joint functions recovered (day 16). The area under curve (AUC) for increase in joint diameter was calculated. The rats were sacrificed and the tissue levels of reduced glutathione and thiobarbituric acid reactive substances were measured. Histological analysis of the joint was also carried out. The effect of LP ( 5 and $25 \mathrm{mg} / \mathrm{kg}$ ) and diclofenac $(5 \mathrm{mg} / \mathrm{kg})$ given on alternate days was evaluated on the parameters mentioned.

Results: LP produced a dose-dependent reduction in AUC for increase in joint diameter and the time required to attain the normal joint functions as compared to the arthritic controls. Treatment with LP normalized the levels of oxidative stress markers and preserved tissue architecture. The protection afforded by LP was comparable to that with diclofenac.

Conclusion: The present study shows that by inhibiting inflammation, LP fraction of latex of C. procera ameliorates functional limitations in arthritic rats.
\end{abstract}

Keywords: Arthritis, C. procera, functional limitations, inflammation, oxidative stress

\section{Background}

Arthritis is a leading cause of disability in adults that affects activities of daily living. It is characterized by pain, immobility, stiffness and joint incapacitation as a result of various pathologies. The major goal of treatment in various forms of arthritis is to decrease clinical symptoms, prevent damage to the joint and to maintain joint functions through the use of non-steroidal and steroidal anti-inflammatory drugs and other pain relieving agents [1].

Latex of the plant C. procera comprises of several constituents including proteins (LP) that exhibit anti-inflammatory and analgesic properties [2,3]. Previously our laboratory has demonstrated the efficacy of LP in ameliorating joint dysfunction, inhibiting the release of mediators and to preserve joint architecture at the time of peak inflammation in arthritic rats [4]. Based on these findings we designed this time-course study to evaluate the effect of LP on inflammation index, joint function recovery time and parameters like markers of oxidative stress, joint tissue histology at the time of functional recovery in arthritic rats.

\section{Methods}

The isolation of proteins from C. procera latex as described earlier includes latex collection in distilled water, centrifugation, dialysis and lyophilization [4]. The study was performed in Wistar albino rats of either sex (150 to $180 \mathrm{gm}$ ) already trained to climb a staircase. The approval of Institutional Animal Ethics Committee of All India Institute of Medical Sciences was obtained (541/IAEC/10).

Arthritis was induced in rats by single intra-articular injection of $0.1 \mathrm{ml}$ of Freund's complete adjuvant (FCA) in the left ankle joint (day 0).

Following groups $(n=6)$ were included:

Group I: Normal Control (NC), saline injected in joint. Group II: Arthritic Control (FC), FCA injected in joint. Group III \& IV: Arthritic rats given LP (5 mg/kg, LP5; 25 mg/kg, LP25).

Group V: Arthritic rats given diclofenac (5 mg/kg, D5).

LP and diclofenac were given intravenously and orally $30 \mathrm{~min}$ and $1 \mathrm{hr}$ before injecting FCA respectively and then every alternate day. The joint diameter and functional parameters given below were scored before injecting FCA, daily for first 3 days and then every alternate day till day 16, a time when these scores normalized in arthritic control. A time-course for increase in joint diameter from day 0 values was plotted and the area under 
Kumar et al. Musculoskeletal Biology 2014,

curve (AUC) as an index of inflammation was determined [5]. The animals were sacrificed on day 16 , joint tissue dissected out and stored at $-80^{\circ} \mathrm{C}$ for biochemical analysis. A similar set of 3 rats per group was included in the study to evaluate the effect of drugs on joint histology on day 16 [4].

As described earlier, the motility and stair climbing ability (SCA) were scored 0 when the rats avoided touching the ground and did not climb any step. The dorsal flexion pain (DFP) was scored 1 each for squeaking and leg withdrawal while flexing the ankle joint and the test was performed five times at an interval of $5 \mathrm{~s}$. The SCA, motility and DFP scores in normal rats were 3,2 and 0 while in arthritic rats the maximum joint function impairment was represented by the scores 0,0 and 10 respectively [4]. The time to attain the SCA and motility score equivalent to that in NC group was recorded.

The levels of reduced glutathione (GSH) and Thiobarbituric acid reactive substances (TBARS) were measured by the methods of Ellman [6] and Ohkawa et al., [7] respectively and histological analysis was carried out as described earlier [4].

The values are given as mean \pm SEM and the groups were compared by ANOVA and post hoc test (LSD). Median DFP scores in different groups were compared by Kruskal-Wallis test. SPSS program (version 11.5) was used for statistical analysis and the statistical significance was considered at $p \leq 0.05$.

\section{Results}

The intra-articular injection of FCA elicited an inflammatory response where an AUC for increase in joint diameter over a period of 16 days was $10.36 \pm 0.53$ against $0.33 \pm 0.01 \mathrm{~mm}$.d in NC group (Figure 1A). Treatment of arthritic rats with LP produced a dose-dependent reduction in the AUC that was accompanied by improvement in motility, stair climbing ability. The present time course study shows that it took $14.00 \pm 0.89$ and $15.33 \pm 0.66$ days respectively for the motility and SCA scores in FC group to revert to normal values while in LP25 group these scores normalized in $7.50 \pm 0.67$ days (Figure 1B). The median DFP scores in groups FC, LP5, LP25 and $D 5$ were $4.5,3,2$ and 2 respectively on day 12 and 0 in all the groups on day 16. Arthritis is well known to be associated with oxidative stress in the inflamed joint tissue. The effect of LP was evaluated on the markers of oxidative stress namely GSH, a cellular antioxidant and TBARS, an index of lipid peroxidation and compared with the standard antiinflammatory drug, diclofenac. In FC group the level of GSH was $178.00 \pm 6.12 \mu \mathrm{g} / \mathrm{g}$ and TBARS was $194.83 \pm 8.43 \mathrm{nmol} / \mathrm{g}$ against $366.66 \pm 11.02 \mu \mathrm{g} / \mathrm{g}$ and $77.5 \pm 8.44 \mathrm{nmol} / \mathrm{g}$ respectively in NC group on day 16 . Treatment with LP normalized these levels in a dose-dependent manner. The effect of LP25 was found to be comparable to that of standard anti-inflammatory drug diclofenac (Figure 2). Figure 3 shows the histological analysis of the inflamed joint on day 16 where edema formation and cellular infiltration were observed in arthritic rats. Like diclofenac, these changes were attenuated by the treatment with LP and the tissue architecture was preserved.
A

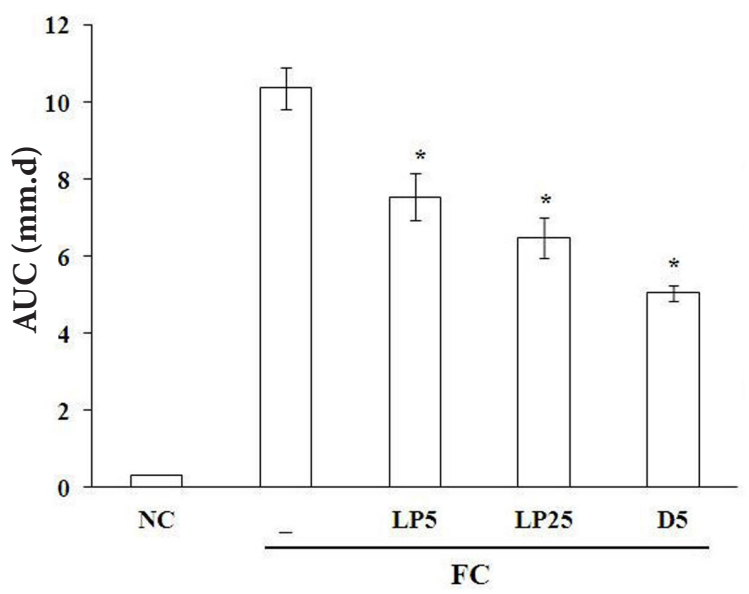

B $\square$ Motility $\square$ Stair Climbing ability

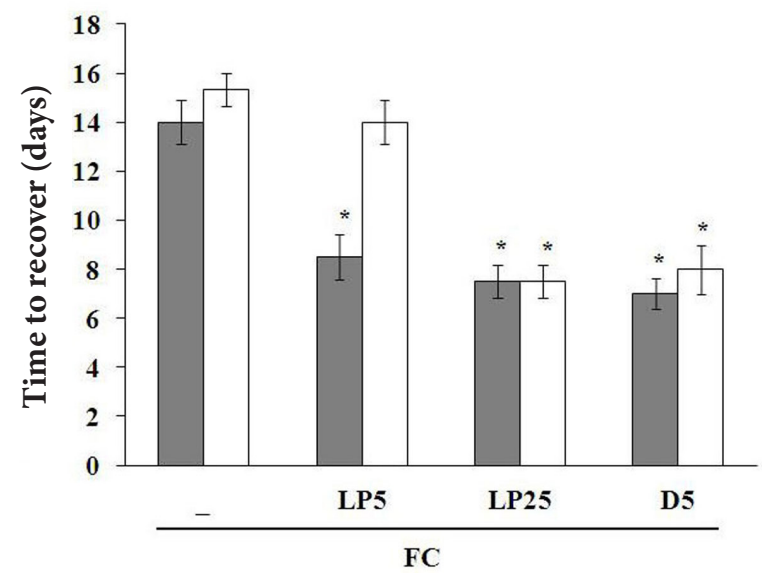

Figure 1. Effect of LP on inflammation index (AUC) (A) and on joint function (motility and SCA) recovery time (B) in arthritic rats. ${ }^{*} \mathrm{p}<0.001$.

\section{Discussion}

Protein fraction of latex of the plant C. procera has been shown to exhibit anti-inflammatory and anti-hyperalgesic properties in arthritic rats [4]. The present study was carried out to evaluate the beneficial effect of $L P$ in restoring joint functions in arthritis. Intra-articular injection of FCA produced a marked increase in AUC for increase in joint diameter as compared to the normal controls where saline was injected. As a result of joint inflammation and hyperalgesia, the animals avoided weight bearing on inflamed limb and experienced difficulty in moving and climbing. Treatment with LP produced a dose-dependent reduction in AUC along with significant reduction in the time to attain functional recovery. As reported earlier, there was improvement in motility, stair climbing ability and reduction in pain on flexion of the inflamed joint with LP treatment [4]. Both SCA and motility scores in LP treated arthritic rats normalized much earlier as compared to the DFP score thus 

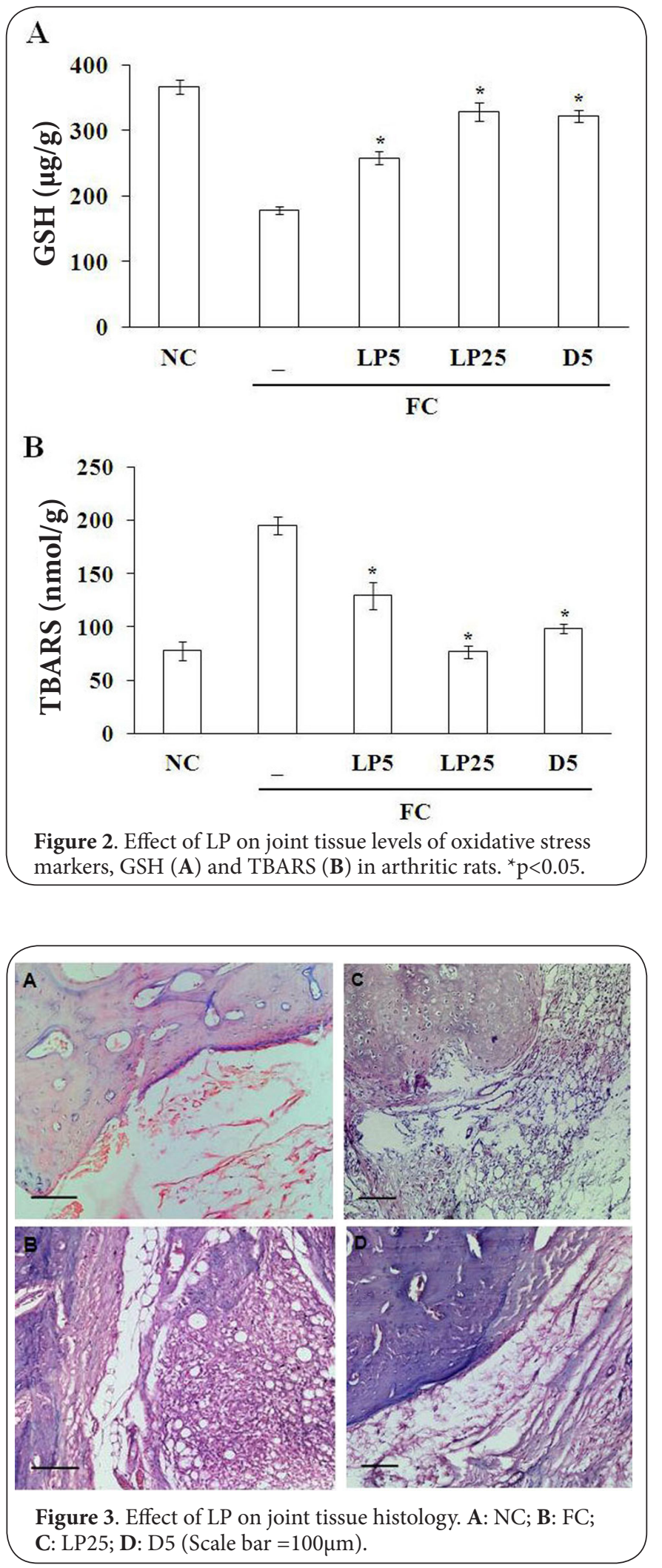

corroborating the earlier findings on temporal disassociation of activity depression and allodynia. Both inflammation and pain have been shown to contribute to decreased activity in rodents that could be reversed by NSAIDs [8].

Oxidative stress plays a key role in the pathogenesis of various inflammatory diseases including arthritis [9]. Reactive oxygen species (ROS) generated in response to an inflammatory stimulus bring about damage to various cellular components, affect intracellular signaling pathways and expression of genes involved in the perpetuation of inflammation. ROS are well known to bring about damage to cartilage, extra-cellular collagen and contribute to joint degeneration [10]. In accordance with our previous study, normalization of levels of oxidative stress markers-GSH, TBARS and tissue architecture was also observed at the time of functional recovery following treatment with LP and diclofenac [4]. In contrary to the findings in rat, NSAIDs are used to provide symptomatic relief in arthritic patients, however, their use does not impede disease progression and joint injury [11].

Thus, the present study shows that like diclofenac, LP fraction of C. procera latex alleviates functional limitations in arthritis by inhibiting inflammation, pain and maintaining oxidative homeostasis.

\section{Competing interests}

The authors declare that they have no competing interests.

Authors' contributions

\begin{tabular}{|l|c|c|c|c|}
\hline Authors' contributions & VLK & PC & RMO & MVR \\
\hline Research concept and design & $\checkmark$ & -- & -- & -- \\
\hline Collection and/or assembly of data & $\checkmark$ & $\checkmark$ & $\checkmark$ & -- \\
\hline Data analysis and interpretation & $\checkmark$ & $\checkmark$ & -- & -- \\
\hline Writing the article & $\checkmark$ & -- & -- & -- \\
\hline Critical revision of the article & $\checkmark$ & -- & -- & $\checkmark$ \\
\hline Final approval of article & $\checkmark$ & $\checkmark$ & $\checkmark$ & $\checkmark$ \\
\hline Statistical analysis & -- & $\checkmark$ & -- & -- \\
\hline
\end{tabular}

\section{Acknowledgement}

This work was funded by DST under Indo-Brazil S \& T programme of Cooperation. M.V.R. is also grateful to the Brazilian Council for Scientific Development (CNPq) for financial support (RENORBIO and UNIVERSAL). The Senior Research Fellowship to P.C. from Department of Biotechnology, New Delhi during the study period is acknowledged.

\section{Publication history}

Senior Editor: Shigeru Kotake, Tokyo Women's Medical University, Japan.

Received: 21-Oct-2013 Revised: 03-Dec-2013

Accepted: 18-Dec-2013 Published: 07-Jan-2014

\section{References}

1. Crofford LJ. Use of NSAIDs in treating patients with arthritis. Arthritis Res Ther. 2013; 15:S2.

2. Alencar NM, Oliveira JS, Mesquita RO, Lima MW, Vale MR, Etchells JP, Freitas CD and Ramos MV. Pro- and anti-inflammatory activities of the latex from Calotropis procera (Ait.) R.Br. are triggered by compounds fractionated by dialysis. Inflamm Res. 2006; 55:559-64. | Article | 
Kumar et al. Musculoskeletal Biology 2014,

PubMed

3. Soares PM, Lima SR, Matos SG, Andrade MM, Patrocinio MC, de Freitas CD, Ramos MV, Criddle DN, Cardi BA, Carvalho KM, Assreuy AM and Vasconcelos SM. Antinociceptive activity of Calotropis procera latex in mice. J Ethnopharmacol. 2005; 99:125-9. | Article | PubMed

4. Kumar VL, Chaudhary P, Ramos MV, Mohan M and Matos MP. Protective effect of proteins derived from the latex of Calotropis procera against inflammatory hyperalgesia in monoarthritic rats. Phytother Res. 2011; 25: 1336-41. | Article | PubMed

5. Nagai $N$, Fukuhata $T$, Ito $Y$, Tai $H$, Hataguchi $Y$ and Nakagawa K. Preventive effect of water containing magnesium ion on paw edema in adjuvantinduced arthritis rat. Biol Pharm Bull. 2007; 30:1934-7. | Article | PubMed

6. Ellman GL. Tissue sulfhydryl groups. Arch Biochem Biophys. 1959; 82:707. | Article | PubMed

7. Ohkawa $\mathrm{H}$, Ohishi $\mathrm{N}$ and Yagi K. Assay for lipid peroxides in animal tissues by thiobarbituric acid reaction. Anal Biochem. 1979; 95:351-8. I Article | PubMed

8. Suhail MS, Christianson C, Koehrn F, Malkmus SA, Mitchell W, Corr M and Yaksh TL. Effects of long term polyarthritis and subsequent NSAID treatment on activity with disassociation of tactile allodynia in the mouse. Neurocomputing. 2012; 84:47-52. | Article | PubMed Abstract | PubMed Full Text

9. Mirshafiey $A$ and Mohsenzadegan $M$. The role of reactive oxygen species in immunopathogenesis of rheumatoid arthritis. Iran J Allergy Asthma Immunol. 2008; 7:195-202. | Article | PubMed

10. Hitchon CA and El-Gabalawy HS. Oxidation in rheumatoid arthritis. Arthritis Res Ther. 2004; 6:265-78. | Article | PubMed Abstract | PubMed Full Text

11. Ballou LR and Wang BWE. Nonsteroidal anti-inflammatory drugs. In Firestein GS, Budd RC, Harris ED Jr, Mclnnes IB, Ruddy S, and Sergent JS (Eds.), Kelley's text book of Rheumatology. Saunder's Elsevier, Philadelphia. 2009; 1:833-861.

\section{Citation:}

Kumar VL, Chaudhary P, Oliveira RM and Ramos MV.

Calotropis procera latex proteins ameliorate functional limitations associated with adjuvant induced inflammation in rat. Musculoskelet Biol. 2014; 1:1. http://dx.doi.org/10.7243/2054-720X-1-1 